\title{
A Study on Behavior of Tuned Mass Dampers Using Water Tank to Reduce Vibrations of Buildings from Earthquake
}

\author{
[ Panumas Saingam and Arthit Petchsasithon]
}

\begin{abstract}
At the present time, an earthquake is one of the problems for the high-rise building structures. This paper presents an analysis and an examination of Tuned Mass Damper (TMD) in order to study the possibility of using the water tank as the TMD. The finite element method is used as a tool in structural analysis. A study of four, eight and twelve story-three dimensional reinforced concrete buildings with water tank placing on the roof is evaluated. The total mass of the whole system including water tank, water, beams,columns and slabs are considered. The behavior of the tank subjected to both El-Centro 1940 and Chichi 1999earthquake data are studied under the condition of full water within a tank. The lateral displacements of the building without water tank are compared with the building with full water tank. In conclusion, use of the water tank is found to be able to reduce vibrations from earthquake in some cases.
\end{abstract}

Keywords - tuned mass dampers,water tank, earthquake, ground acceleration, building

\section{Introduction}

Currently, all around the world including Thailand encounters an earthquake that is one of the problems for the high-rise building structures. This is a challenge for all structural engineers to develop the system for alleviating this hazard. There is one interesting system widely used to reduce the seismic force called Tuned Mass Dampers (TMD). In many buildings, water tank placed on the top of the roof can be used as Tuned Mass Damper (TMD).Therefore, this research analyses and examines the possibility of using the water tank as the TMD by varying the weight of water tank as TMD to find the optimum mass ratio $(\mu)$ to maximum reduce vibration from earthquake.The four, eight and twelve storybuilding are studied under the El-Centro1940 and ChiChi1999 earthquakes by comparing the lateral displacements of the building without water tank with the building with full water tank. The height of water tank is varied from $1 \mathrm{~m}$ to $8 \mathrm{~m}$ to vary the mass of TMD $\left(\mathrm{m}_{2}\right)$.

Panumas Saingam/Master degree student

Department of Civil Engineering/Faculty of Engineering /King Mongkut's Institute of Technology Ladkrabang

Thailand

Arthit Petchsasithon/Lecturer

Department of Civil Engineering/Faculty of Engineering /King Mongkut's Institute of Technology Ladkrabang

Thailand

\section{Analytical Investigation}

The aim of this paper is to study the optimum mass ratio $(\mu)$ for the mass of the tank $\left(\mathrm{m}_{2}\right)$ to the total mass of the main building $\left(\mathrm{m}_{1}\right)$ in case of El-Centro1940 and ChiChi1999 earthquakes.

\section{A. Tuned Mass Dampers (TMD)}

TMD system is a device mounted in structure to reduce the effect of vibrations that conceptually is first oscillator (mass of main systems or structures) connected to the second oscillator (mass localized reduction of vibration as water tank,TMD). If adjusted accordingly, the maximum amplitude of the first oscillator would have decreased steadily over time due to some vibration is transferred to the second oscillator.

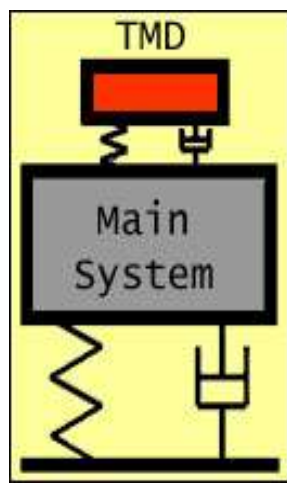

Fig 1. Tuned Mass Dampers system

\section{B. Building Data}

TABLE I. BUILDING DATA

\begin{tabular}{|l|c|c|c|}
\hline \multirow{2}{*}{ Type } & \multicolumn{3}{|c|}{ Column Size } \\
\cline { 2 - 4 } & Column 1-4 floor & Column 5-8 floor & Column 9-12 floor \\
\hline 4 story & $35 \times 35 \mathrm{~cm}^{2}$ & - & - \\
\hline 8 story & $50 \times 50 \mathrm{~cm}^{2}$ & $35 \times 35 \mathrm{~cm}^{2}$ & - \\
\hline 12 story & $65 \times 65 \mathrm{~cm}^{2}$ & $50 \times 50 \mathrm{~cm}^{2}$ & $35 \times 35 \mathrm{~cm}^{2}$ \\
\hline
\end{tabular}

Note :

Story height $=3$ meters.

Span of columns $=4$ meters.

Beam Size $=25 \times 55 \mathrm{~cm}^{2}$ all buildings. 
Proc. of The Second Intl. Conf. On Advances in Civil, Structural and Mechanical Engineering - ACSM 2015 Copyright $($ Institute of Research Engineers and Doctors, USA .All rights reserved.

ISBN: 978-1-63248-074-3 doi: 10.15224/ 978-1-63248-074-3-35

\section{Water Tank Data}

TABLE II. WATER TANK DATA

\begin{tabular}{|c|c|c|}
\hline Type & Size & Leg of water tank \\
\hline Concrete & $4 \times 4 \mathrm{~m}^{2}$ & $20 \times 20 \mathrm{~cm}^{2} \times 1 \mathrm{~m}$ \\
\hline
\end{tabular}

Note :The height of water tank is changed from $1 \mathrm{~m}$ to $8 \mathrm{~m}$ to vary the mass of TMD $\left(\mathrm{m}_{2}\right)$.

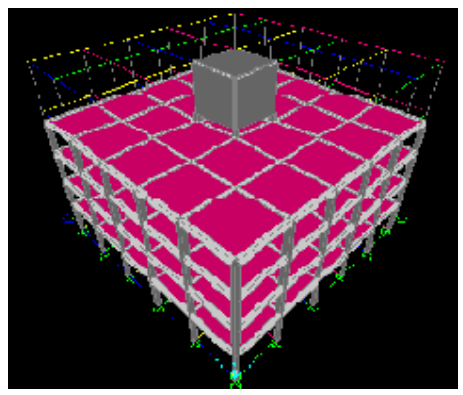

Fig 2. Four story building placing water tank on the roof

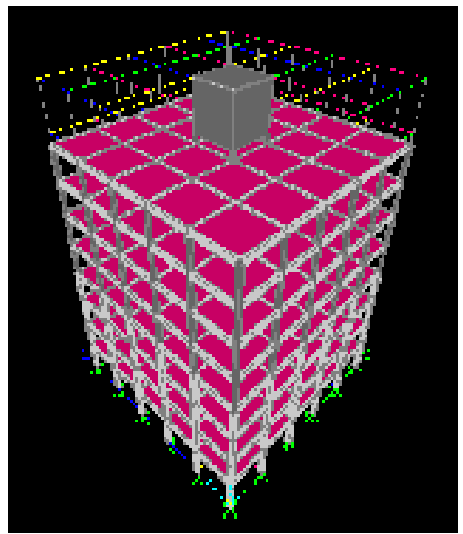

Fig 3. Eight story building placing water tank on the roof

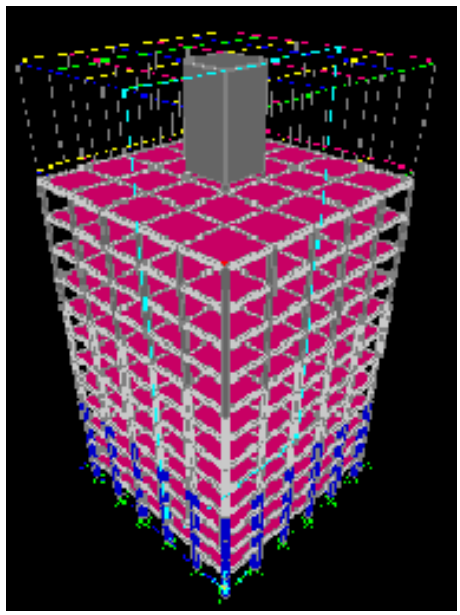

Fig 4. Twelve story building placing water tank on the roof

\section{Earthquake Data}

\begin{tabular}{|c|c|c|c|}
\multicolumn{3}{c}{ TABLE III. } & EARTHQUAKE DATA \\
\hline Type & Station & Year & $\boldsymbol{P G A ( g )}$ \\
\hline El-Centro & El-Centro & 1940 & 0.31 \\
\hline ChiChi & Jiji & 1999 & 0.22 \\
\hline
\end{tabular}

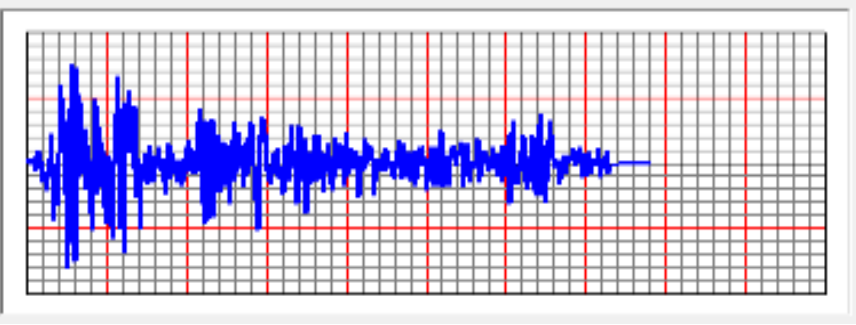

Fig 5. El-Centro1940 ground acceleration

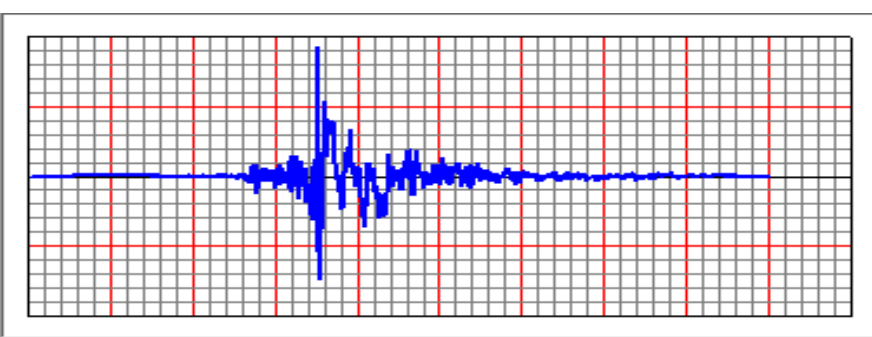

Fig 6.ChiChi 1999 ground acceleration

\section{Result and Discussion}

The responses from both the El-Centro1940 and ChiChi1999 earthquakes of four, eight and twelve storybuildings with water tank are considerably better than those without water tank in some cases. However, using water tank as tuned mass damper does not reduce the displacement in every case.

\section{A. Four story building}

Although, the lateral displacement of the building is less than allowable lateral displacement $(\mathrm{L} / 500)=2.4 \mathrm{~cm}$ in all cases, the response displacement in four story building without damping is different from the building with damping.Varying the height of water tanks results in different lateral displacement. In some cases, lateral displacements of the buildings with water tanks are higher than those of buildings without water tank. This means that for some certain heights of water tank, the natural frequency of the building, $\omega=(\mathrm{k} / \mathrm{m})^{1 / 2}$, is close to the frequency of the earthquakes themselves which is known as resonance phenomenon. 
Proc. of The Second Intl. Conf. On Advances in Civil, Structural and Mechanical Engineering - ACSM 2015

Copyright $\odot$ Institute of Research Engineers and Doctors, USA .All rights reserved.

ISBN: 978-1-63248-074-3 doi: 10.15224/ 978-1-63248-074-3-35

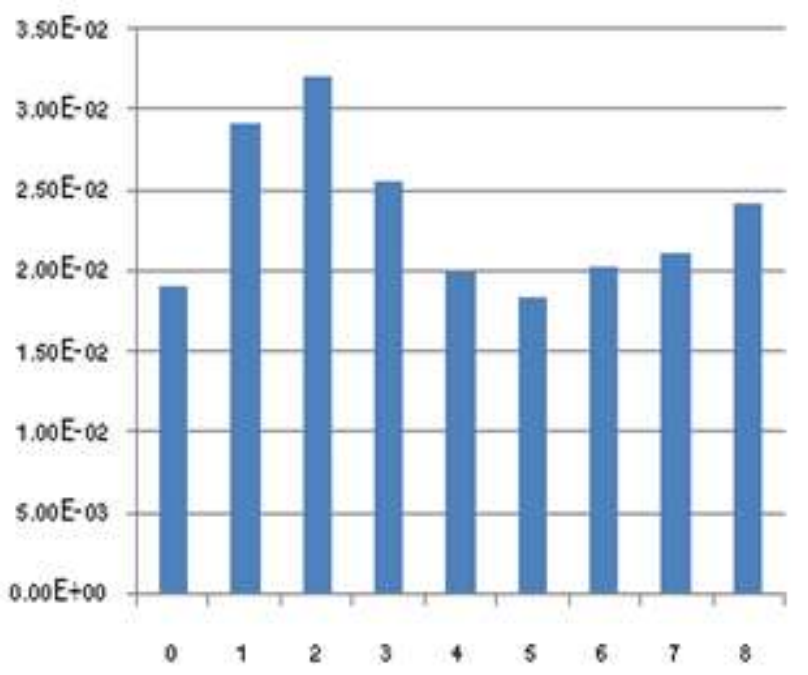

Fig 7. El-Centro 1940 without damping

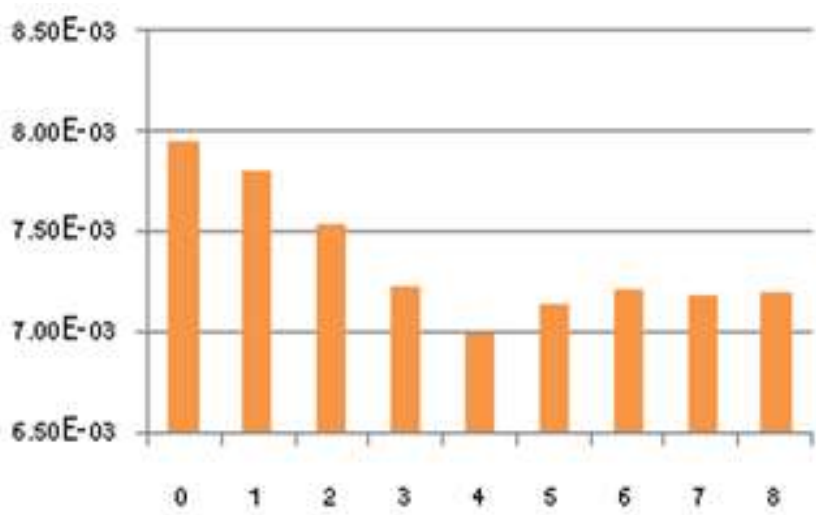

Fig 8. El-Centro 1940 with damping

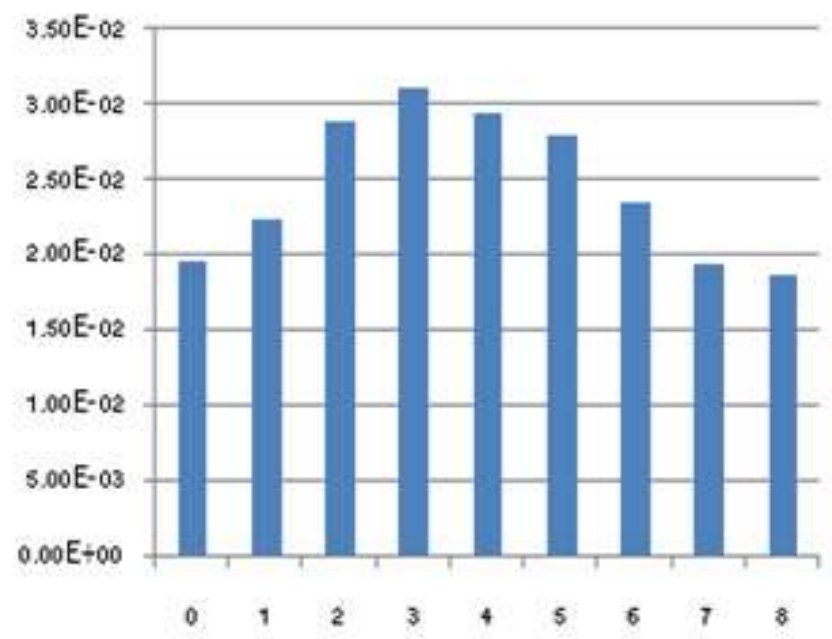

Fig 9.ChiChi 1999 without damping

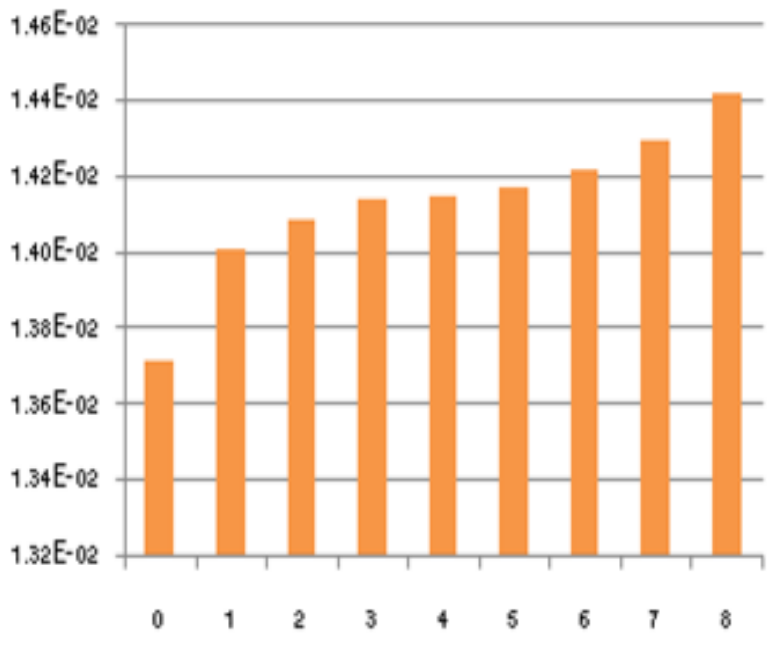

Fig 10.ChiChi 1999 with damping

The result of displacement in case of four story in the research illustrates that for building with damping subjected to El-Centro 1940 earthquake, the optimum mass ratio, $\mu$,between the mass of the water tank $\left(\mathrm{m}_{2}\right)$ and the total mass of the main building $\left(\mathrm{m}_{1}\right)$ is 0.104 .

\section{B. Eight story building}

For the eight story-building without damping, the lateral displacement of the building with water tank are higher than that without water tank for both El-Centro 1940 and ChiChi 1999 earthquakes. On the other hand, for the buildings with damping, the lateral displacement of the building with water tank are less than that without water tank. For both building with and without water tank, the lateral displacement for both El-Centro1940 and ChiChi 1999 earthquake are less than allowable lateral displacement $(\mathrm{L} / 500=4.8 \mathrm{~cm})$ in all cases.

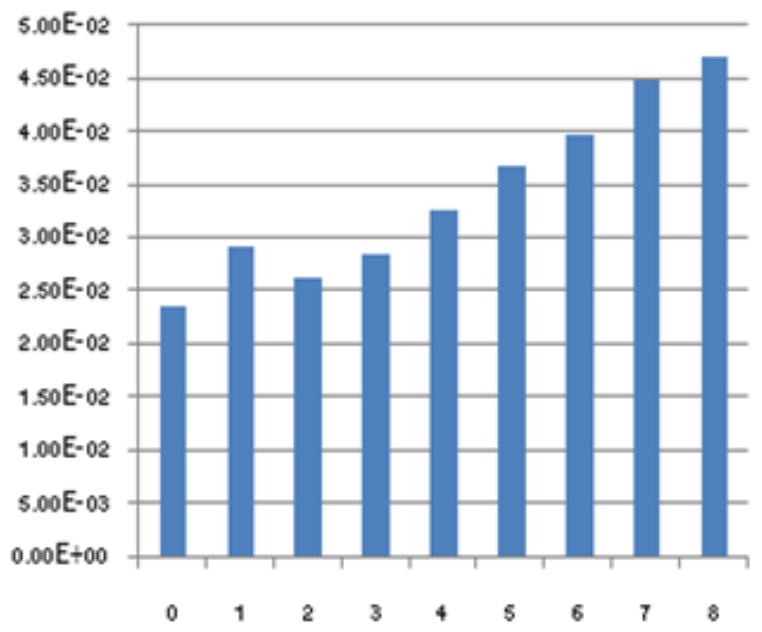

Fig 11. El-Centro 1940 without damping 
Proc. of The Second Intl. Conf. On Advances in Civil, Structural and Mechanical Engineering - ACSM 2015 Copyright $($ Institute of Research Engineers and Doctors, USA .All rights reserved.

ISBN: 978-1-63248-074-3 doi: 10.15224/ 978-1-63248-074-3-35

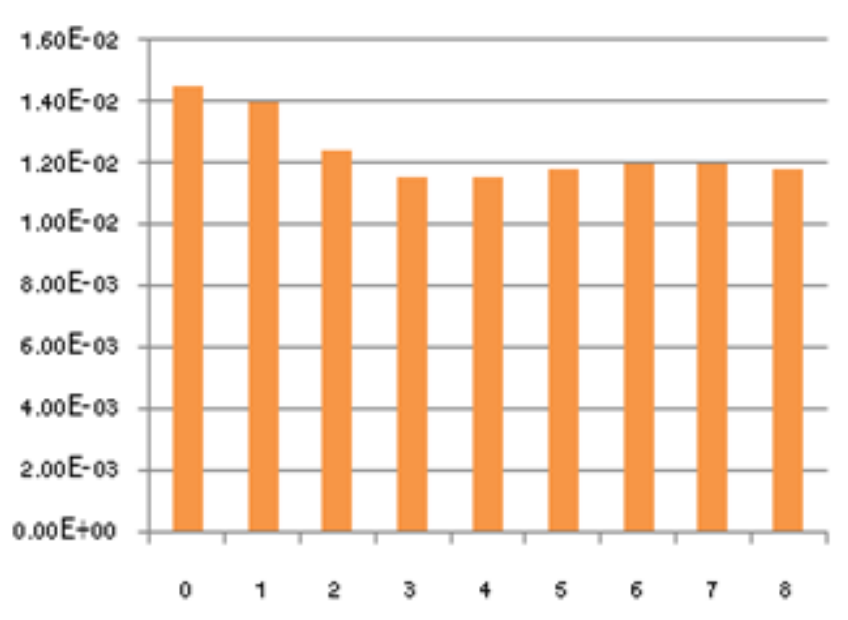

Fig 12. El-Centro 1940 with damping

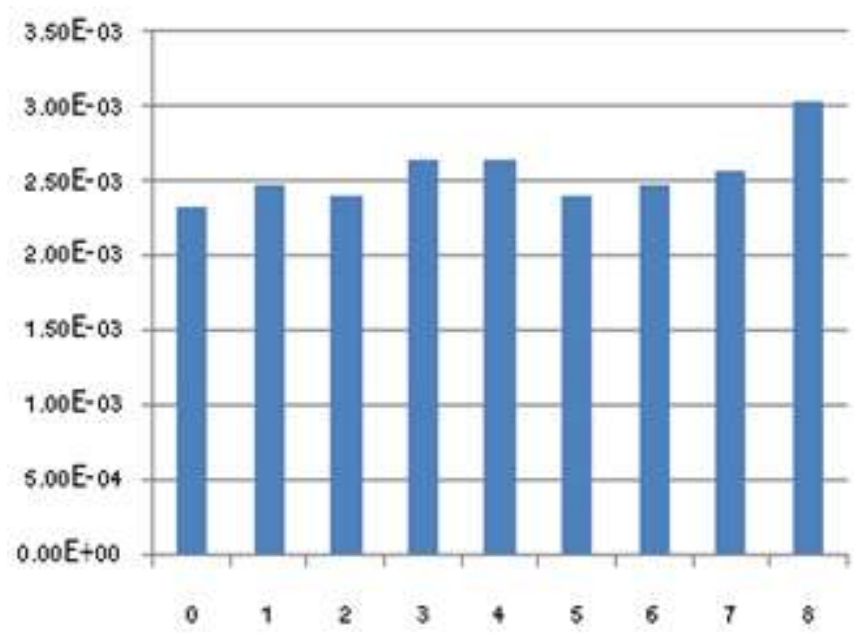

Fig 13.ChiChi 1999 without damping

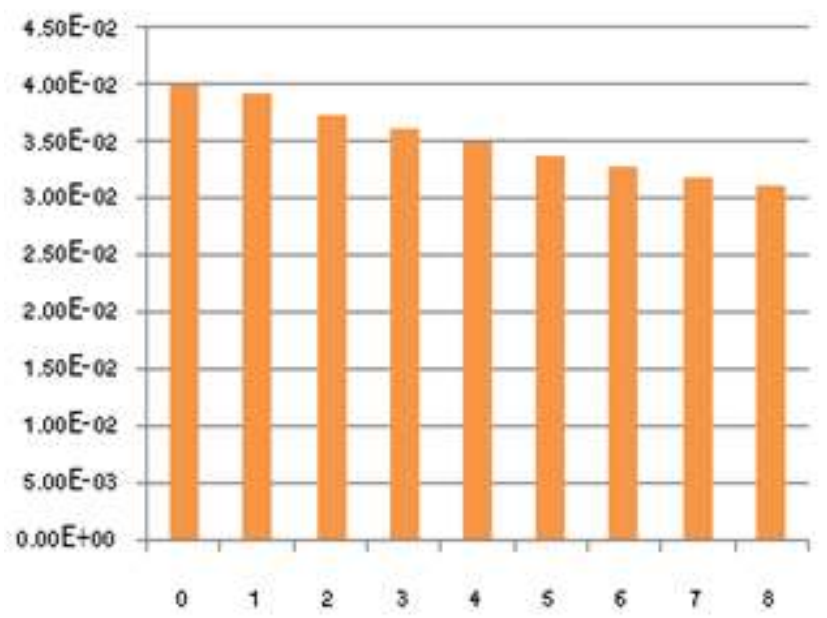

Fig 14.ChiChi 1999 with damping
In eight story case, the mass ratio $(\mu)$ of the mass of the water tank $\left(\mathrm{m}_{2}\right)$ to the total mass of the main building $\left(\mathrm{m}_{1}\right)$ equaling to 0.083 is the most suitable ratio for using as a mass damping system to reduce vibrations (Tuned mass damper, TMD) under the conditions of El-Centro 1940 and ChiChi 1999 seismic.

\section{Twelve story building}

In this study, the tallest building without damping shows similar results to the case of eight floors. For the building without damping, the lateral displacement of the building with water tank are higher than that without water tank in some cases for both El-Centro 1940 and ChiChi 1999 earthquakes. On the other hand, for the buildings with damping, the lateral displacement of the building with water tank are less than that without water tank. The lateral displacement for both ElCentro1940 and ChiChi 1999 earthquake are less than allowable lateral displacement $(\mathrm{L} / 500=7.2 \mathrm{~cm})$ only in the building with damping case.

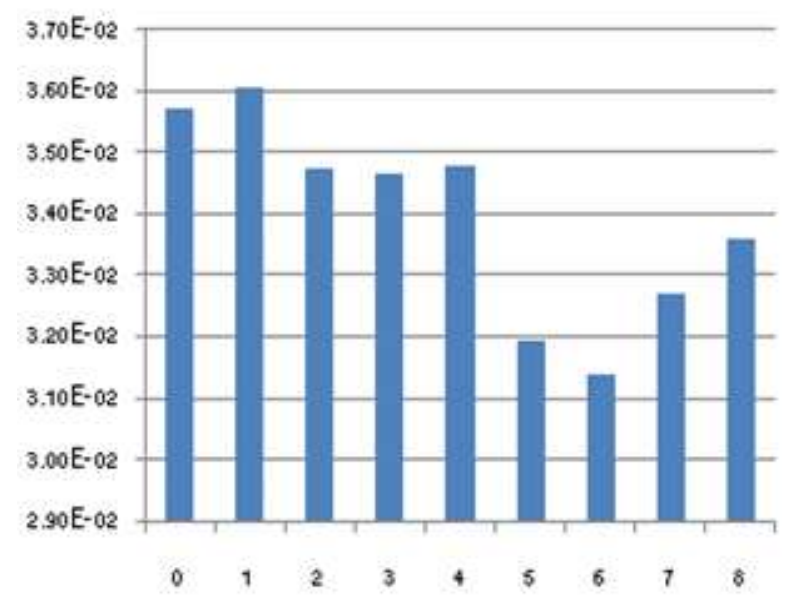

Fig 15. El-Centro 1940 without damping

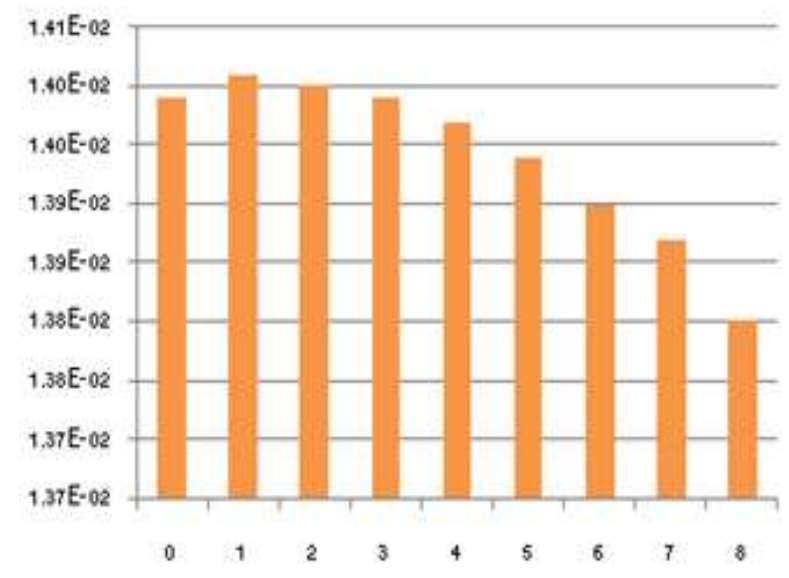

Fig 16. El-Centro 1940 with damping 


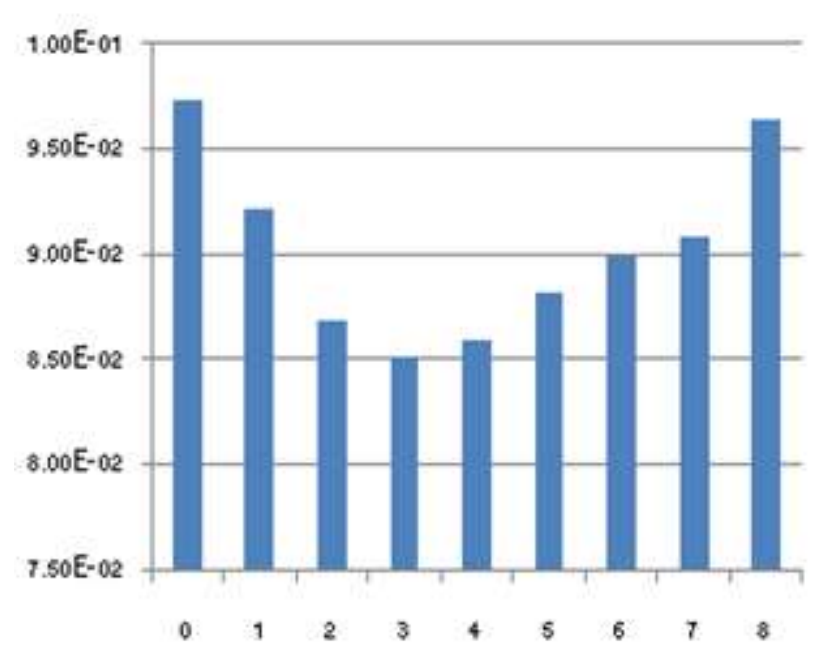

Fig 17.ChiChi 1999 without damping

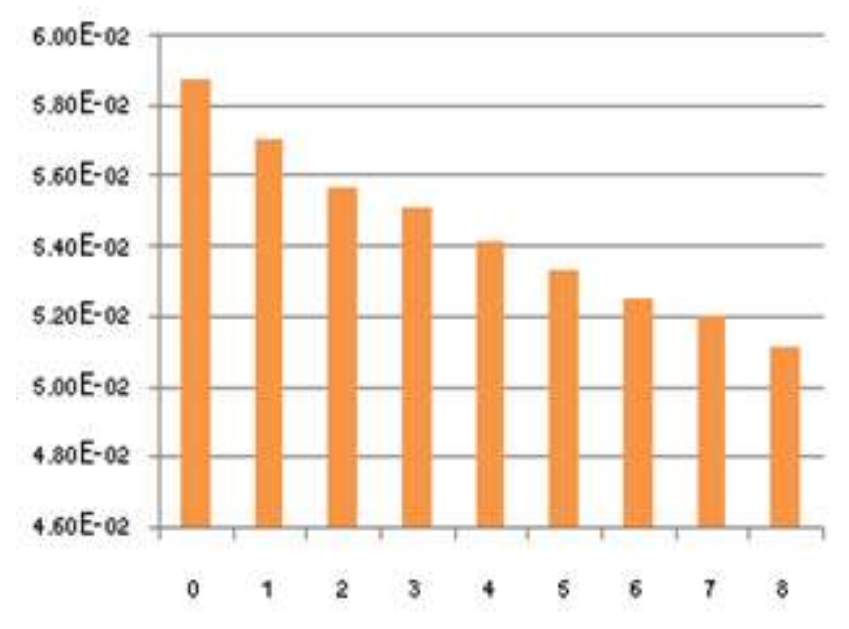

Fig 18.ChiChi 1999 with damping

The result of the last model exhibits that the mass ratio $(\mu)$ between the mass of the water tank $\left(\mathrm{m}_{2}\right)$ and the total mass of the main building $\left(\mathrm{m}_{1}\right)$ equaling to 0.051 is the most suitable value for using as tuned mass dampers system to reduce vibration from earthquake under both El-Centro 1940 and ChiChi 1999.

\section{Iv. Conclusion}

The research using finite element in the analysis of the3-D reinforced concrete building illustrates that,in some cases, lateral displacements of the buildings with water tanks are higher than those of buildings without water tank. This means that for some certain heights of water tank, the natural frequency of the building, $\omega=(\mathrm{k} / \mathrm{m})^{1 / 2}$, is close to the frequency of the earthquakes themselves which is known as resonance phenomenon. This phenomenon increases the lateral displacement of the buildings.

\section{Acknowledgment}

This research has been successfully accomplished with the continuous guidance and support from theresearch advisor Dr. Arthit Petchsathon. Moreover, I would also like to thank lecturers of Department of Civil Engineering. Faculty of Engineering King Mongkut's Institute of Technology who encouraged and supported me throughout my studies in the past.

\section{References}

[1] Bandivadekar T.P., "Mass distribution of multiple tuned mass dampers for Vibrationcontrolofstructures", Department of Civil Engineering, Indian Institute of Technology Bombay, Powai, Mumbai., 2012.

[2] Abhinav Alva.,"EXPERIMENTAL AND FINITE ELEMENTS ANALYSIS OF A TUNED MASS ABSORBER FOR VIBRATION ISOLATION", ARPN Journal of Engineering and Applied Sciences, 2011.

[3] T.H. Nguyen and N.Haritos, "Performance of Distributed Multiple Viscoelastic Tuned Mass Dampers for Floor Vibration Applications", Department of Infrastructure Engineering, The University of Melbourne, VIC 3010, Australia, 2011.

[4] Abhinav Alva, Ravish and Gangadharan K.V., "EXPERIMENTAL AND FINITE ELEMENTS ANALYSIS OF A TUNED MASS ABSORBER FOR VIBRATION ISOLATION", Department of Mechanical Engineering, National Institute of Technology Karnataka, Surathkal, India, 2011.

[5] Yozo Fujino andPennung Warnitchai, "Optimal Tuned Mass Damper for Seismic Applications and Practical Design Formulas" Engineering Structures Volume 30, Issue 3, March 2008, Pages 707-715, 2008.

[6] Amir M.Kaynia, John M.Biggs และDaniele Veneziano.1981 "Seismic Effectiveness of Tuned Mass Dampers" Journal of the Structural Division, Vol.107, No. 8, August, pp. 1465-1484, 1981.

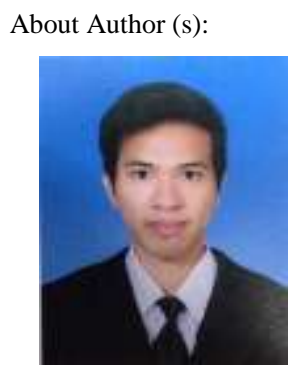

\section{Panumas Saingam}

Organizations and experience :

Master degree student in Department of Civil Engineering, King Mongkut's Institute of Technology Ladkrabang, Thailand(2014-2015) and Internship student researcher in Department of Civil Engineering,Tokai University, Japan (2013)

Topic research interest : Earthquake Engineering, Structural design and Vibration Control

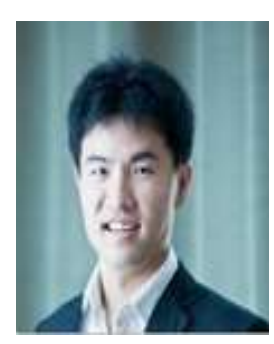

\section{Arthit Petchsasithon}

Organizations and experience : Lecturer in Department of Civil Engineering, King Mongkut's Institute of Technology Ladkrabang,

Thailand(from 2009),

Professional Engineerings Exam committee in Structural (from 2011) and Structural Design (from2001) Topic research interest :Non-linear Shell Structures, Finite Element and Structural dynamic 